\title{
Climate Change: Moving the Paris Agreement from Words to Deeds
}

\author{
Miguel Schloss $\mathrm{a}^{*}$ \\ a President of Surinvest Ltda. (Chile), Former Executive Director of Transparency International, and Director of Corporate \\ Planning of World Bank \\ *Corresponding author's email address:
}

\section{A R T I C L E I N F O}

Received: 19-05-2016

Accepted: 13-06-2016

Available online: 14-07-2016

Keywords: Climate Change; Environment; Energy, Renewable, International Law.

JEL Classification:

\section{A B S T R A C T}

Economic and social development the world has experienced in the last couple of centuries has been unprecedented, propelled by technological advances that have overcome famine and extended life expectancy in much of the world. This has been reflected in productivity gains in agriculture, industrial development, advances in communications, transport and energy never experienced in much of recorded history. But this has brought increases in C02 emissions since the industrial age, whose full implications are as yet somewhat unpredictable. However, an increasingly widespread consensus has emerged that there is the need to reverse these emissions to prevent global average temperature increases to less than 2 Celsius. The Agreement reached by the 195 countries in climate talks in Paris requires an overhaul of historic proportions for energy policies worldwide and investment of the order of $\$ 16.5$ trillion of spending on renewables and efficiency, as well as carbon capture and storage through 2030 , to meet the agreed targets outlined, as estimated by the International Energy Agency. In essence, the deal aims at limiting global temperature increase since the Industrial Revolution of the 18th and 19th centuries to 2 degrees Celsius (3.6 degrees Fahrenheit), while calling on nations to "pursue efforts to limit the temperature increase to 1.5 degrees." The Paris Agreement provides a framework for such effort, and will require significant reductions in hydrocarbons investments, increases in emissions costs, reduction in deforestation, intensive reengineering of energy sources in use, and profound changes in transport systems. None of this will take place on its own or be politically, economically and technically easy. Henceforth emphasis must focus on how to move from words to deeds in a manner that does not affect negatively economic development. This article is focused on four areas that need special attention to ensure that future efforts can adequately address concerns of efficiency and effectiveness, which have hitherto received scant attention, with consequent limited progress and results in climate change actions. As there are few precedents in this emerging area, this article is based on benchmark analysis the author has conducted to assist several Governments in designing policies to deal with the emerging issues climate change is posing.

This is an open access article under the terms of the Creative Commons Attribution License 4.0, which allows use, distribution and reproduction in any medium, provided the original work is properly cited.

IELR: The agreement reached by 195 countries in Paris require an overhaul of historical proportions for energy policies worldwide and investments of some US\$16.5 trillion of spending in renewables and efficiency, and carbon capture up to 2030 to meet the agreed targets. 


\subsection{Process vs. substance}

The multitude of international conventions, agreements, standards, including the Paris Agreement, have tended to be hailed as historical and transformational endeavors. While it is undeniable the legitimization that such agreements have given at senior-most levels, in this case to environmental concerns, it is less clear what such efforts (including previous ones on the subject) have resulted in tangible outcomes on the ground or addressed the underlying forces that have produced the environmental trends we have observed.

Almost inevitably, such efforts generate a panoply of ratification, accession, approval arrangements, establishment of ad hoc working groups, development of guidelines and other vehicles to help prepare plans, monitor them, follow-up meetings - of which the above-mentioned Agreement has a heavy dose.

It is thus easy to get blinded with so much activity, and confuse it with actual results or real progress. Surely, tracking and follow-up are necessary, but in no case sufficient to achieve impact. While they may be attractive because they are easy to observe, they are at best intermediate steps towards producing the results one ultimate wants to achieve, and thus should not inadvertently detract attention away from the substantive issues that need addressing, and in the process generate incentives for monitoring and controlling -- leaving institutions, policies and other vehicles of action hopelessly behind, and a far cry from what is needed to deal with the emerging and changing conditions.

\section{$2.0 \quad$ Enabling conditions}

Fighting global warming requires a broader and more nuanced understanding of how different sectors interact with each other. Merely adopting new environmental laws, creating new commissions or environmental regulatory institutions, or launching another 'campaign' will not get the job done.

The issue is part a larger dysfunction -- the failure of policies, institutions and governance arrangements to properly link incentives and emerging concerns on externalities, so that investments and consumption on the one hand, and public sector resource management, on the other, respond to the delivery of public goods and private services demanded by society.

If international experience has anything to teach us from what has been put in place so far, it has become evident that there are limited precedents with proven records of performance to go by. In the end each country will need to develop its own institutional infrastructure, both for energy, transport and other policies to have a strategic framework on environmental concerns for the country's engagement and face the development challenges of the years ahead.

Hitherto, oftentimes countries have inadvertently introduced competing and duplicative policies: operating at the national, regional (EU for example) and the international levels (leading, for example, to wetting up of more than 15 different climate change ODA funds) with limited attention on standards and approaches. The establishment of distortionary pricing policies and subsidies, difficult to manage, or earmarked taxes on carbon trades to fund adaptation: taxing one public good (that governments want more of) to pay for another.

Key in all this, at least for a good many developing countries, is the need be vigilant to avoid developing institutionally-intensive arrangements in institutionally-weak conditions, since "institution-building" mentioned in the Paris Agreement is a long and difficult road. Wherever possible one must develop a policy framework that enables key economic actors and civil society to interact organically, without too many constraints and avoid moving to a complicated regulatory system (where duplication, offsetting incentives, etc. are all too common).

The rule should be minimize the rules, use pricing where at all possible, and allow any legitimate additional costs of compliance to environmental standards to be recouped through output prices - thereby avoiding energy development paths that become costly and complicated.

\subsection{Technologies}

At the end of the day, "green" and renewable sources of energy must become a growing part of a carbon free energy development, since they tend to have lower $\mathrm{CO} 2$ emissions than traditional sources, as can be seen in the following graph: 


\section{Environment: Emissions \& Local Ecosystems}

There are large differences in emissions by energy source

CO2 Emissions by energy type ( $\mathrm{kg}$ carbon equivalent/ TEP)

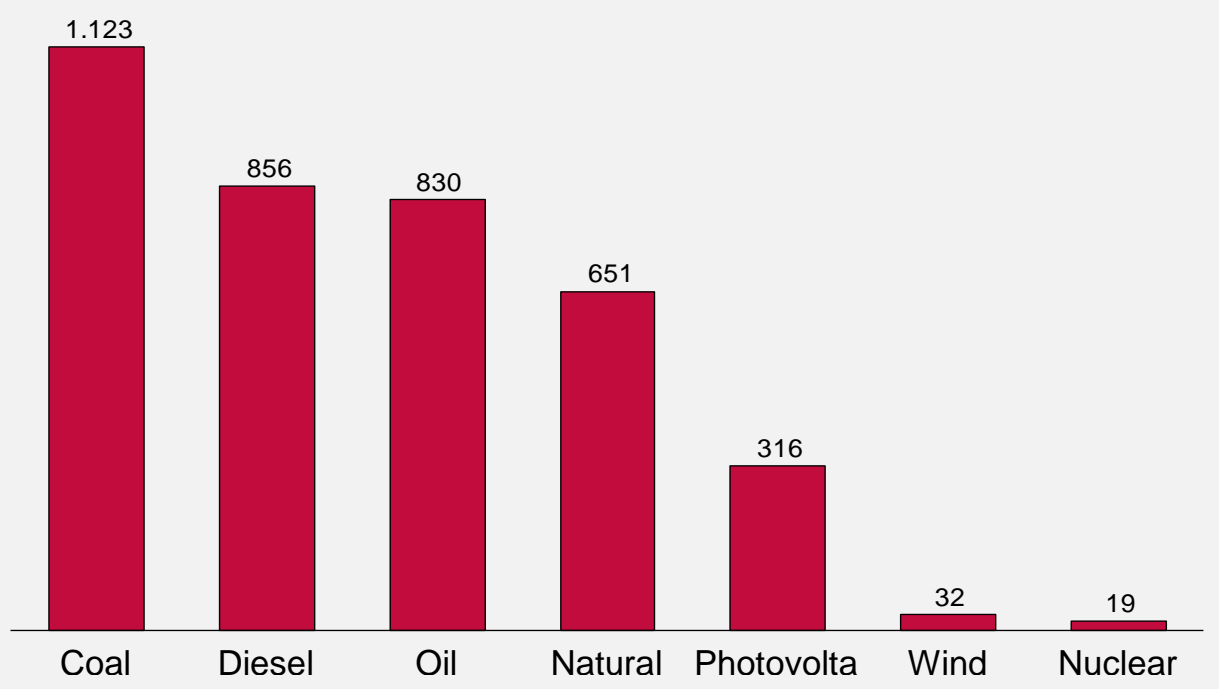

Sources: CNE (Chile Energy Commission): J. Cheyre "Policy \& Strategic Challenges"; M. Tockman "Current Situation \& Perspective 2012"

For the time being, though, such sources are still relatively more expensive, and thus constitute in many cases situation-specific solutions, depending on local conditions (such as wind regimes or solar radiation levels), and appropriate for limited load factor requirements. In all, they illustrate their relative high cost compared with traditional energy generation sources, the consequent limits for funding outside the private sector, and the special skills and approaches they generate.

These are the ingredients of early development of any new course of action, which merit attention as they develop further, and become at least partial solutions for the energy requirements of the future. Therefore, these options involve trade-offs that need to be properly assessed -- not only for energy development, but also more broadly in terms of their interaction with agricultural, urbanization, and ultimately for economic development.

The Agreement could, on the other hand, provide the conditions for enhanced R\&D to develop such technologies to further reduce costs and level the playing field vis-à-vis traditional sources of energy. Some "green" technologies are closing the gap in terms of cost...and become even more attractive when considering CO2 emissions as can be observed in the following graph: 


\section{Security of Supply in Power Generation}

\section{...AND become even more attractive when considering $\mathrm{CO} 2$ emissions}

"Green" Cost Comparison, Production Costs (USD/MWh \& CO2 Emissions in Tons/MWh at 25 USD/ton)

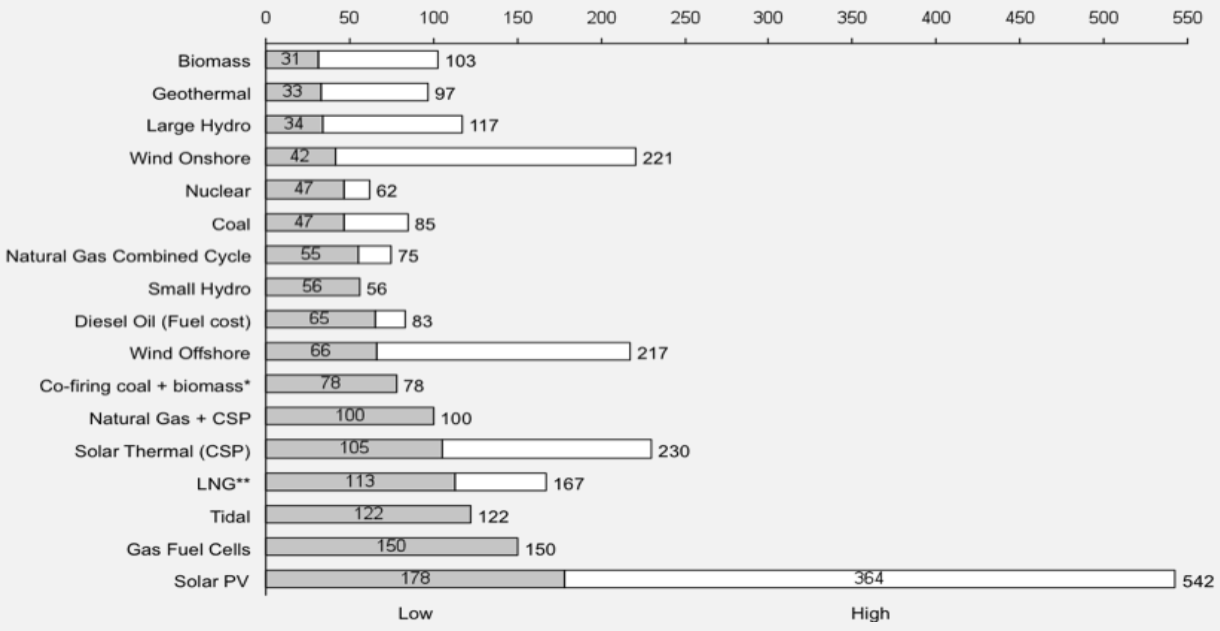

Sources" IEA Energy Technology Perspectives, 2012; Ormat Technologies, Inc.

However, the internalization of climate change externalities is a relatively "recent" development and the world is still "struggling" for operational solutions for clean energy production such as Carbon Capture and Sequestration. Nonetheless, any future investments in traditional technologies must consider and allow for integration of upcoming technologies.

A long term strategy for energy is bound to lie in technological substitution of the current capital stock of nonliquid fossil fuels towards a greater mix of coal fired plants (which are bound to stay with us for a while), LNG based plant, geothermal and hydro electricity with renewables likely playing a niche role in the energy mix.

\subsection{Managing the transition}

The sheer massiveness of the resources theoretically required for overhauling existing systems merit special attention in terms of their transitional arrangements, which by the looks of it, have not been defined explicitly in the Agreement itself. Three areas that come to mind:

- Though not clearly recognized, the Agreement seems to accept as a fact of life that the 2, let alone the 1.5 degrees Celsius paths are most difficult to achieve, and accordingly envisions financing adaptation programs (i.e. living with the problem in the near term). This is of course a pragmatic stand, though not with its own pitfalls, as it involves mobilizing large resources for more "traditional" investments (storm barriers, resettlement and even more conventional infrastructures), which could be conveniently relabeled to be "counted" as part of the climate change agenda. As such investments tend to be capital intensive and carried out through public sectors with considerable room for discretionary powers, they can easily fall prey to corruption and deflection of resources.

- As the Agreement is grounded on "nationally determined contributions", it will leave important tracts of the global problems "out of the radar", such as maritime, air, the Arctic and Antarctic continents, which have their special environmental issues. For instance, the shipping industry emits more $\mathrm{CO} 2$ per year than any (including the larger) European countries.

- The global economic context with its continuing deleveraging process may well keep global conditions in a constrained growth path, with consequent low commodity prices, and with it low fossil fuel prices (making them highly competitive with non-traditional sources, quite apart of their large sunk costs), and reducing drastically the surplus generation of an important part of developing countries relying on mining and other extractives, thereby depriving them from their main source of financing (and diminishing prospects of retrofitting such investments to reduce their energy intensity).

\subsection{Conclusions}

All things considered, given the large investment, institutional, governance and complex policy implications, the Agreement appears to be more aspirational than operational. 
It is built on existing institutions that don't have much of a track record of handling these type issues, at least in the scale that may be required, and which may well prove to be obsolete or too inflexible to deal with important global changes, including a more dynamic, agile and creative world. Accordingly, the question remains whether the current set up in many countries will actually be able to engage the forces unleashed by the swift technological change.

On the other hand, over the longer term other technological and institutional options not currently envisioned may present themselves and it is worth considering how and when this might happen.

For the time being, though, the transition may take some time, as the sunk costs of traditional sources of energy will not be that easily overcome, and thus hydrocarbon solutions (though cleaner ones) are bound to be with us for a while as is the consensus projections summarized in the following graph of World Energy Supply by fuel sources (in MToe), including oil (for transport) and gas (for power generation):

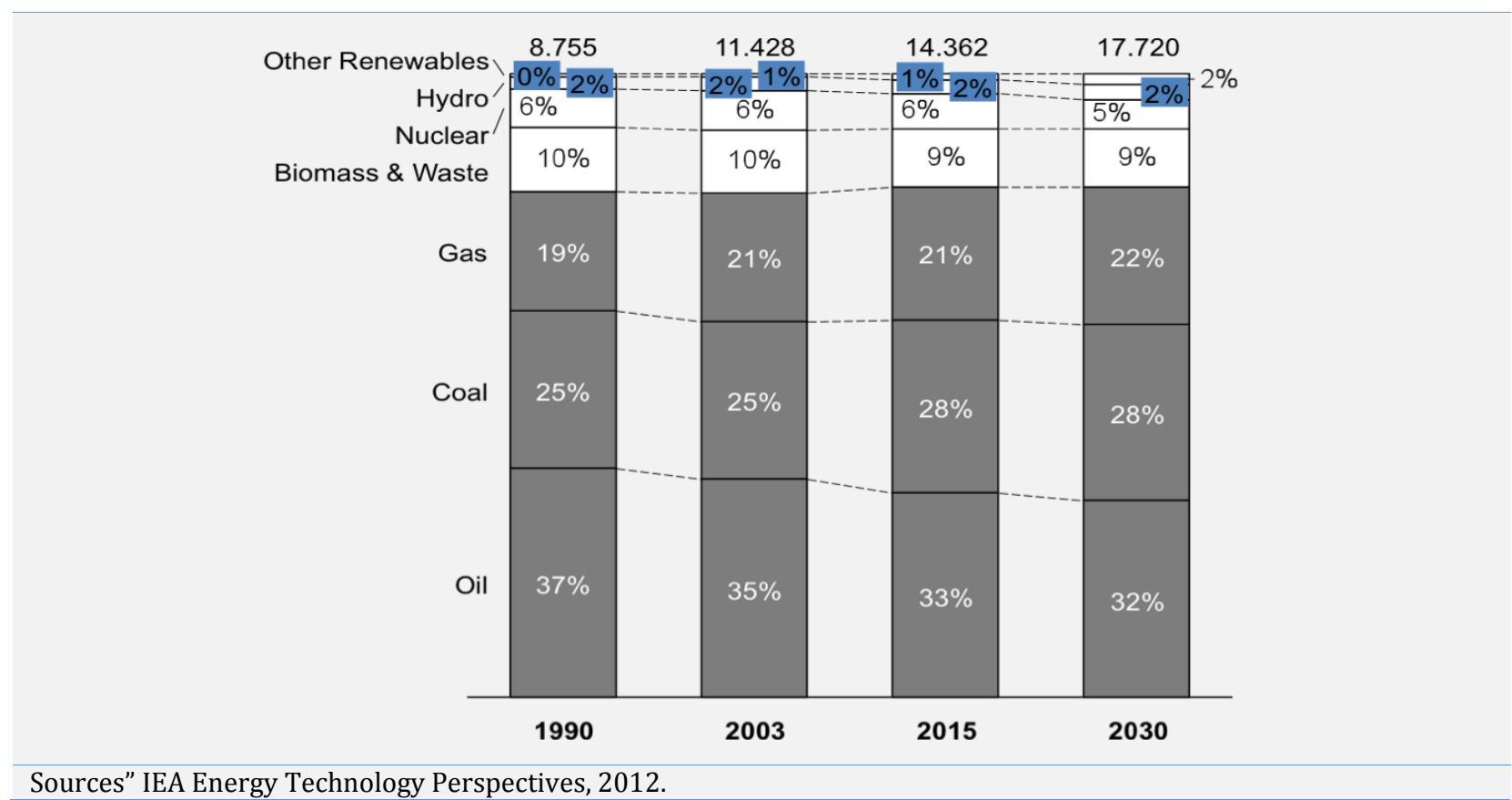

Much of the complexity of policy design in energy and environment stems from a multiplicity of objectives. Moreover, the spillover effects of the policies pursued by any single country, or group of countries - relating mainly to environmental impact and competitiveness concerns - means that there is a potential distinction between national and collective objectives. Ultimately to reconcile the trade-offs in designing policies, special consideration will be needed on:

- Efficient resource allocation, requires that both energy producers and users face prices that reflect its scarcity value-which for nonrenewable resources stems from direct production costs as well as the opportunity cost of present consumption in terms of future consumption foregone-and any associated externalities. When externalities spill across national borders, however, they create important distinctions between global and national perspectives on efficiency: they matter for the former, but not the latter.

- Competitiveness and terms of trade concerns, with growing fears of disadvantaging domestic producers in world markets, they have increasingly become important in designing policy measures bearing on energy.

- Fiscal considerations also arise in shaping fiscal polices toward energy, particularly as hydrocarbons constitutes among the largest balance of payments (either in imports or exports) 
in most countries. Accounting for nearly 45 percent of global oil demand, for example, the G7 collectively is likely to have significant power in the world market: measures to restrict demand may bring about further reduction in world oil prices that raises their citizens' welfare, in effect transferring to them part of the resource rent that suppliers of oil would otherwise enjoy. The converse of any such gain, however, is a corresponding loss to oil exporting countries.

- Revenue, cost compliance and administration concerns affect interactions with the wider tax system, more generally, and impact both the choice of instrument and the level at which taxes are set, and in any event, should henceforth incorporate compliance and associated costs so that they are recuperated in pricing.

\section{References}

Asia-Pacific Economic Cooperation (APEC) (Tokyo, Japan) Nov. 2008 International Energy Issues (supply and demand forecast, energy security, environmental and institutional implications). "Criteria vs. Processes for Identifying, Managing and Evaluating International Initiatives

Cayman Financial Review, (USA) \& Oil, Gas \& Energy Law Intelligence ((OGEL - U.K.) Oct. 2015 - "Policy framework for Extractive industries' Performance"

Electricidad (Santiago, Chile) Mar. 2014 - Generación de energía y disminución de la huella del carbono - Cómo lograr la compatibilidad (Energy and Carbon Footprint - How to align objectives)

Instituto de Gobierno y Gestión Pública - Universidad de San Martin USMP (Lima, Perú) Dec. 2015 "Experiencias Internacionales para Fortalecer la Gobernabilidad (International Experiences for Strengthening Governance)" ISSN 2414-4991

Pulso and DF (Santiago, Chile) - 01 Oct. 2014 - Energía y medio ambiente: ¿objetivos en conflicto? (Energy and Environment: Objectives in Conflict?)

The World Bank (Washington, DC, USA), Oct. 2006. The Energy Efficiency Investment Forum: Scaling Up Financing in the Developing World. Energy Sector Management Assistance Program (ESMAP)

The World Bank (Washington, DC, USA), Jan. 2008 -- Achieving Low Carbon Growth for the World.

United Nations Framework Convention on Climate Change (FCC - Conference of the Parties - (Paris, France) 12 Dec. 2015 